\title{
RESPONDING TO TERRORIST ATTACKS AND NATURAL DISASTERS: A CASE STUDY USING SIMULATION
}

\author{
Pavel Albores \\ Duncan Shaw \\ Aston Business School \\ Operations and Information Management Group \\ Birmingham,. B4 7ET UK
}

\begin{abstract}
The heightened threat of terrorism has caused governments worldwide to reconsider their plans for responding in the immediate aftermath to large-scale catastrophic incidents. This paper discusses the use of discrete event simulation modeling to understand how a Fire Service might position its resources before an attack takes place, to best respond to a combination of different attacks at different locations if they happen. Two models are built for this purpose. The first model deals with mass decontamination of a population following biological or chemical attack - aiming to study resource requirements (vehicles, equipment and manpower) necessary to meet performance targets. The second model deals with the allocation of resources across regions - aiming to study cover level and response times, analyzing different allocations of resources, both centralized and decentralized. Contributions to theory and practice are outlined.
\end{abstract}

\section{INTRODUCTION}

In the wake of the terrorist attacks in New York $\left(11^{\text {th }}\right.$ September 2001), Madrid ( $11^{\text {th }}$ March 2004) and London ( $7^{\text {th }}$ July, 2005), governments worldwide are reconsidering their preparation for the aftermath of a major terrorist attack. This paper reports on work performed in support of developing a national capability to respond to a major and catastrophic terrorist attack by getting the right personnel with the right skills and equipment to the right locations within a desired time and be able to respond for a particular duration. Planning this national capability is a complex task, especially when it requires responding to any combination of incidents happening simultaneously at any combination of locations.

At a simple level, discrete event simulation (DES) (Greasley 2004) can help decision makers to understand the systemic effects within a single incident e.g. how many people can be decontaminated within the required time if emergency personnel/equipment arrive (or not) as planned. However, DES can also help with understanding more complex scenarios about interdependencies between critical incidents happening simultaneously at different locations but requiring the same personnel and/or equipment. In our context, a decision maker in any country in the world could use the model to investigate the effect of the geographical spread of resources on response times for three concurrent incidents happening, as well as investigate what happens once the resources arrive at the incident.

This paper discusses an application which used two generic DES models to support thinking about a national response to critical incidents. To set the scene, we first review the background to this project and then review literature on this topic. We then explore the appropriateness of DES models for providing insight to this problem. We then detail a case study, the models built, experimentation and report on the nature of results. Discussion of the modeling requirements, constraints of the approach, and future developments conclude the paper.

\section{BACKGROUND}

This paper was inspired by our modeling support for a program established to support the development of capabilities for a Fire and Rescue Service to respond to terrorist attacks and natural disasters.

In many countries (certainly the one in which this project was conducted) the Fire Service is an integral part of the emergency response to critical incidents: First, they are able to mobilize a very large number of qualified personnel at very short notice. Second, the role of the firefighter often includes duties beyond fire fighting, for example search and rescue, flooding assistance and now emergency response to events such as bomb attacks or the release of biological agents.

As part of the development of capabilities to respond to an attack, our project aimed to inform decision making over the acquisition of equipment and training for three 


\section{Albores and Shaw}

types of incident: mass decontamination of a population following a Chemical, Biological Nuclear or Radiological (CBRN) incident; urban search and rescue (USAR) in, for example, a collapsed building; flooding i.e. moving masses of water resulting, from natural or man-made events. An example of the type of scenario that the Fire service can be faced with is provided in the following hypothetical scenario involving three concurrent incidents: Incident 1 - decontaminate 20,000 people within 18 hours of them becoming contaminated. Incident 2 - have 300 urban search and rescue trained fire-fighters and kit to a location prepared to deal with a collapsed building within 1 hour and be able to sustain that response for 24 hours - and do this while $70 \%$ of the regions resources attend Incident 1 . Incident 3 - within 3 hours of becoming aware of a flooding incident, respond for 20 hours with 600 trained firefighters.

The allocation of national resources across regions is often competitive and risk-based, but needs to happen in such a way as to provide an acceptable level of response for the entire country. Thus, justification for the amount spent, and the regional allocation, needs to be based on the likelihood of critical incidents occurring (which is outwith the scope of this paper) and the operational performance to respond.

Assessing operational performance was a task ideally suited to DES where the systemic interaction between the process and input factors could be modeled to understand the profile of the response to each incident. This allowed easy, cheap, fast, safe and repeatable consideration of total solutions (of interacting variables) through experimental comparison of alternative input factors. It would also provide insight to important control factors which influence performance.

Two models were built for the project. The first model dealt with mass decontamination incidents (of the flavour detailed in Incident 1, above). It investigated the size of manpower required to achieve desired levels of operational performance. The second model dealt with the allocation of resources across regions (so they could respond to Incidents 1,2 and 3, above). In many countries limited resources can be shared across regions and so planning this for concurrent events is needed (e.g. in the case of the multiple train bombings in Madrid). From this sharing of resources, emerges the need to know what is the response profile over time, that is, how many resources can be made available, and at what times these can arrive to the scene of an emergency. In brief, the second model investigated levels of response over the life of the incident (weight of attack) and response time ( time to first firefighter being on scene and operational) under different combinations of incidents happening simultaneously.

It is important to note that this paper aims to show the methodology used to tackle this complex problem. It does not show the results of any particular application. Hence, to illustrate the methodology we use a hypothetical case study that illustrates the approach. We use publicly available data to give the model realism, using the authors' own assumptions where public data is not available - hence we do not discuss data collection nor validation. All the incidents/scenarios tested are hypothetical and have been generated specifically for the hypothetical case. The case study data could reflect any city/region anywhere in the world.

Before the DES models are discussed in-depth, the literature available on this topic is reviewed.

\section{LITERATURE REVIEW}

Simulation has been applied to a number of applications in the emergency response area. Previous Winter Simulation conferences have dedicated special tracks to this issue (See <http://www. wintersim.org> for more information). Most of the applications have been in the area of analysis of Accident and Emergency departments in hospitals. In the area of interest for this paper, two main streams have been identified: simulation of mass vaccination and analysis of emergency response times.

\subsection{Mass Vaccination Simulation}

Work in this area is focused on the analysis of mass vaccination exercises, mainly dealing with the analysis of antibiotic delivery in the case of the release of a biological agent.

Aaby et al. (2004) report the simulation of mass vaccination clinic, based on a live exercise by the Montgomery County Department of Health. The paper describes process flow and processing time data, as well as routing probabilities collected during a live exercise . Being a model created for the medical side of emergency response, it includes stages such as triage, registration, education, screening, consultation and vaccination.

Hupert et al. (2002) model an antibiotic distribution centre, adding more detail in terms of low, medium and high prevalence scenarios. By using optimization tools, the model provides the level of manning for the different stations in the process.

It is important to highlight that neither of these models take into account the need to rotate personnel based on the time spent in protective suits.

\subsection{Emergency Response Simulation}

In the area of emergency response the focus has been on analyzing depot location in order to provide an acceptable level of cover for a region. Cowdale (2003) reports the application of simulation to the analysis of fire emergency cover by the Ministry of Defence (UK) in the case of strike action by the fire service. A simulation model was developed to investigate asset utilization and alternative loca- 


\section{Albores and Shaw}

tions. Gul (2005) presents a similar analysis for ambulance response.

Other work has been reported on the more theoretical aspects of emergency response simulation. Jain and McLean (2003) present a framework for the integration of all aspects of emergency response. They argue that since the nature of emergency response is a multi-agency one, it is required that different applications (like the one presented above) can "be systematically integrated together to address overall response" (Jain and McLean 2003). The same authors describe the development of agent dispersion, fire and storm simulations. Brady (2003) goes some way towards this joint analysis in his description of the work carried out in Laporte County, "focused on ... information flows, coordination and response of medical, police and fires resources" (Brady 2003). Farahmand (1997) describes the application of simulation to the analysis of emergency population evacuation, analyzing the "probability of the optimal escape routes".

The above applications reflect the potential of simulation to tackle different aspects of emergency response. The dynamic nature of these type of incidents and the low frequency at which they occur, makes simulation an ideal tool to understand their behavior and to be able to plan for future contingencies.

\section{MODELLING APPROACH}

The simulation models are built in Simul8 ${ }^{\circledR}$ and are linked to an Excel user interface through which the user had full control of all experimental variables. As will be discussed below, experiments can be performed on standard variables (e.g. process times, manpower and equipment availability, and traveling times) as well as some less usual variables (e.g. the order in which regions would respond to major incidents if the resources required could not be fulfilled from the home region, how long after the previous incident would the next incident occur, for how long does a response need to last, and number of non-ambulant people able to be decontaminated simultaneously).

Defining the process flow and agreeing the data to populate the models was a challenge. Working with the simulation team was a facilitator who acted as an interface with the process owners. The facilitator built an assumptions repository in which all data was logged, and against which the simulation model was built. However, during meetings between the simulation team, facilitator, and process owners it became clear that there was great uncertainty over the process, let alone some of the basic input data. This required the development of generic models which were able to adapt to different stakeholders perceptions and desires. Factors made generic, which might be expected to be hard coded, included: order in which regions asked for help from other regions when they were faced with a large incident; location of regions; how much equipment could fit onto a lorry.

As discussed above, the two models are: a model of the mass decontamination process; a model of the geographical distribution of equipment to respond to any incident.

\subsection{Mass Decontamination Model}

The mass decontamination model deals with the process of removing the contaminants from a population immediately after the occurrence of CBRN incident. Casualties arrive to the decontamination centre where they queue to start the disrobing process. They receive a disrobing pack which contains a disrobing suit and a pair of scissors. In this part of the process, the objective is to make people cut off their clothes (as opposed to simply taking them off). This is to avoid contaminant getting into the body through the nose, mouth or eyes. It is thought that up to $80 \%$ of the contaminant is removed at this stage. A "disrobing suit" is provided for people to cover themselves. Once people have removed their clothes, they proceed to the decontamination tent, where they are put under a shower until all contaminant is removed. After the shower stage people are then sent to the re-robing area, where they dry and are provided with a re-robing pack (paper/plastic suit) to leave the decontamination centre. The process is illustrated in Figure 1.

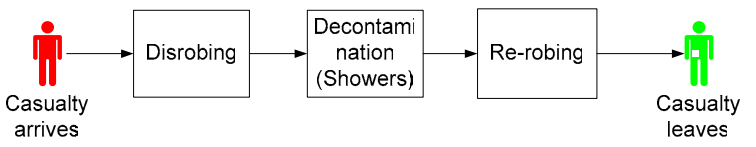

Figure 1: Mass Decontamination Process.

As can be seen, this process deals only with the actual decontamination of people, in contrast to those models presented by Hupert et al. (2002) and Aaby et al. (2004), which include stages such as triage, registration and education. However, in this case, the Fire Service does not carry out these activities in mass decontamination (hence are outside the scope of the model).

For modeling purposes, the decontamination process was divided in three stages: disrobing, decontamination and re-robing. Although in the actual system all three stages occur within the same decontamination tent, they are modeled separately in order to analyze where the bottleneck is.

Inputs to the model (which is shown in Figure 2) are: processing times, number of people to decontaminate, what percentage of these are non-ambulant (in need of stretchers of wheelchairs), inter-arrival times of replenishment material and arrival times of decontamination tents. This last point was particularly important because the arrival of decontamination tents will be staggered, depending on the allocation of these tents across the country. For example, for an event in Region A, the tents belonging to that region 


\section{Albores and Shaw}

can be on the scene and operational in 1-2 hours. Tents coming from the nearest neighboring regions will arrive after 3-4 hours, while those further away will arrive in 5-6 hours. The model "creates" new tents as time passes to simulate their arrival. An example of the code used to create these tents is presented below:

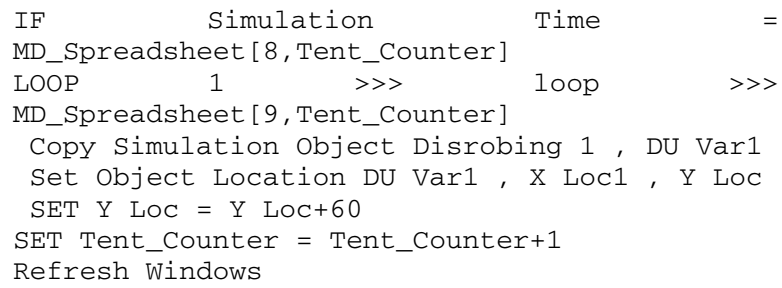

The outputs of this model are the time to treat a population, the time to finish disrobing and the number of fire fighters required to man the tents for the duration of the event. This last parameter is important because the mass decontamination tent is a resource intensive operation. Fire fighters operating in this tent must wear Personal Protective Equipment (PPE) ranging from gas-tight suits with breathing apparatus to simple protective suits. In this case, firefighters can stay from twenty minutes to more than two hours in the different PPE before needing replacement although the details for this incident are given in Table 1.

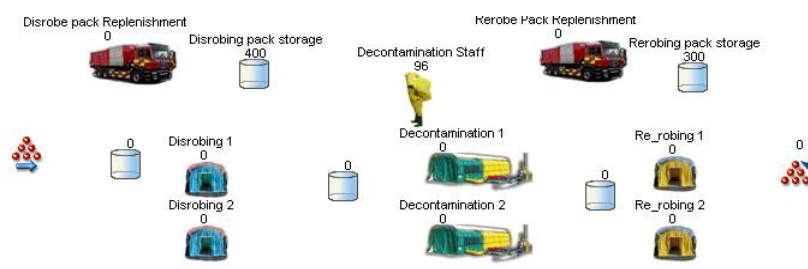

Figure 2: The Mass Decontamination Model

\subsection{Resource Allocation Model}

The next model was focused on the analysis of resource allocation across the country. The reason behind the creation of this model is that in the case of an eventuality, limited resources (emergency equipment) are to be shared across regions. Initial allocation of these resources was planed on the basis of a single event happening in one of the areas. However, there is the need to plan for simultaneous events (for example, in the case of the Madrid train bombings) and to understand the effect of such events on the availability of resources to deal effectively with this concurrency.

\subsubsection{Resource Allocation Model Building}

The model evolved from having nine regions within the country (which were both potential targets and also depots for equipment) to a completely generic model that can be used at the national, regional or local level. The model simulates up to three concurrent events which can happen in any of the locations and which can be of different nature (Mass Decontamination, USAR, or Flooding). The inputs to the model are:

- The name of the locations (can be regions of the country or specific brigades within a region)

- Travel time between locations.

- Resource allocation. How many crews and equipment of each type is allocated to each location.

- Priority/sequence to "borrow" resources from. This allows a region to use its resources first and then start calling resources from other locations in the order specified.

- Scenarios to be analyzed. Which type of event (Mass Decontamination, USAR, Flooding) is happening at which location, when does it start and for how long you need to sustain the presence of the fire service on the site, as well as the number of resources required for each one of these events.

All the inputs are done via an Excel interface, which isolates the user from the actual simulation model.

The model (Illustrated in Figure 3) produces outputs are: initial response time, response profile for each one of the events ("weight of attack") and whether all resources required are obtained.
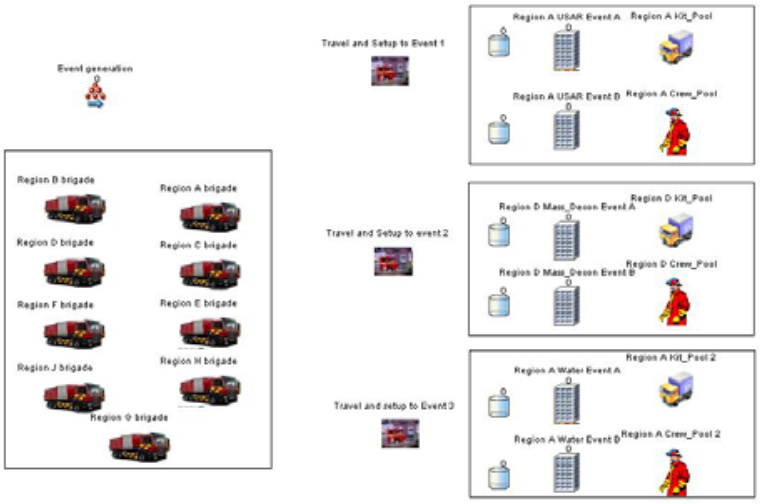

Figure 3: Resource Allocation Model

\subsubsection{Particular Modeling Issues}

Simulation components are used to represent different locations. The component represented a "brigade" which has the following resources: crews, water pumping equipment, mass decontamination equipment and USAR equipment. An example of this component is presented in Figure 4. 


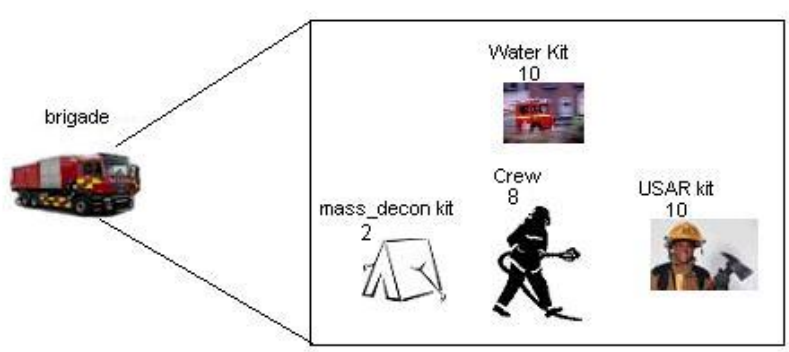

Figure 4: A "Brigade" Component.

A number of visual logic statements are used to allow the model to be generic. This visual logic ranges from reading the names of the locations and assigning them to predefined components representing a location to creating resource pools from which the events will draw the necessary crews and equipment.

Crews and equipment were modeled as resources, while the events were modeled as work centers. The duration of the response required was modeled as work items needing processing. Each work item represents an hour, for which you need the resources in order to process it.'

\section{THE CASE STUDY}

The case study presents hypothetical scenarios that illustrate the type of scenarios that can be analyzed with the models.

A decision had been made to simulate the Fire and Rescue Service response for the following scenario involving three incidents which all start on the same day:

Incident 1 located in Region A starting at time 0:00 hours - have 40 USAR crews (equivalent to 400 USAR trained firefighters and equipment) to any city in the region prepared to deal with a several collapsed buildings within 1 hour of becoming aware of the incident. Within 4 hours of becoming aware of the incident, have an additional 40 USAR crews (400 USAR trained firefighters and equipment) to the location. Be able to sustain that level of response (80 crews and equipment) for an additional 43 hours (ie until 48 hours have passed from first becoming aware of the incident).

Incident 2 located in Region C starting at time 3:00 hours - use the required manpower and equipment to decontaminate 20,000 people within 18 hours of them becoming contaminated with a chemical agent. Assume that firefighters have three types of personal protective equipment (PPE) suits that provide decreasing protection (and that they must start with suit 1 - maximum protection). Although unsure of the precise timings (estimates in Table 1), and so experimentation is required, it is assumed that firefighters use their PPE for the following durations before becoming exhausted and having to be replaced.

Incident 3 located in Region A starting at time 15:00 hours - have 20 water crews (300 water trained firefighters
Table 1: Estimates of PPE Suit Wearage

\begin{tabular}{|c|c|c|}
\cline { 2 - 3 } \multicolumn{1}{c|}{} & $\begin{array}{c}\text { Time able to } \\
\text { spend in PPE suit } \\
\text { before being re- } \\
\text { placed (minutes) }\end{array}$ & $\begin{array}{c}\text { How long after } \\
\text { the incident do } \\
\text { you still need to } \\
\text { work in this suit } \\
\text { (minutes) }\end{array}$ \\
\hline 1 st PPE suit type & 40 & 180 \\
\hline $2^{\text {nd }}$ PPE suit type & 60 & 360 \\
\hline $3^{\text {rd }}$ PPE suit type & 80 & $\begin{array}{c}\text { For the rest of the } \\
\text { incident }\end{array}$ \\
\hline
\end{tabular}

and equipment) to any city in the region prepared to deal with flooding caused by a dam bursting within 3 hours of becoming aware of the incident. Within 6 hours of becoming aware of the incident, have an additional 20 water teams at the location. Be able to sustain that level of response (600 firefighters and equipment) for an additional 12 hours (i.e. until 18 hours has passed from first becoming aware of the incident).

\section{EXPERIMENTATION AND RESULTS}

\subsection{Mass Decontamination Model}

In order to run the model for response time across regions when three overlapping events occur, it is necessary to first study the mass decontamination event, in order to know how many tents and firefighters are required. The results includes here are only an illustration of the type of outputs obtained from the model. The results presented here describe the baseline scenario of 20,000 people to be decontaminated in 18 hours. Two experiments are presented. The first experiment deals with the arrival times and number of mass decontamination tents. Table 2 shows the profile of arrivals to be considered under Incident 1.

Table 2: Initial Profile of Tents Arriving to Incident 2.

The arrival of mass decontamination tents:

\begin{tabular}{|c|c|}
\hline $\begin{array}{c}\text { Time on scene } \\
\text { (mins) }\end{array}$ & $\begin{array}{c}\text { Number of additional } \\
\text { tents arriving }\end{array}$ \\
\hline Initial Response & 2 \\
\hline 60 & 6 \\
\hline 120 & 8 \\
\hline 180 & 6 \\
\hline Total & 22 \\
\hline
\end{tabular}

The arrival pattern described in Table 2 results in an average decontamination time of 18.32 hours, close to the required 18 , but not fully on target. Further experimenting with these values results in the optimal arrival pattern pre- 
sented in Table 3. This pattern was created keeping the total number of tents constant and varying the amount arriving at the different time intervals. The total decontamination time for the profile described in Table 3 is 17.94 in average, requiring 941 firefighters to man the stations.

Table 3: Optimal Arrival Profile for Mass Decontamination Tents

\begin{tabular}{|c|c|}
\hline \multicolumn{2}{|c|}{ The arrival of mass decontamination tents: } \\
\hline Time on scene (mins) & $\begin{array}{c}\text { Number of additional } \\
\text { tents arriving }\end{array}$ \\
\hline Initial Response & 4 \\
\hline 60 & 8 \\
\hline 120 & 4 \\
\hline 180 & 6 \\
\hline Total & 22 \\
\hline
\end{tabular}

The second experiment analyzes the effect of having different percentages of non-ambulant people. The baseline scenario is to have $10 \%$ non-ambulant casualties, and for these to take 10 times as long to decontaminate as an ambulant casualty. Analysis was carried out for scenarios with zero non-ambulants, low amount of non-ambulants (4\%) and high incidence of non-ambulants $(25 \%)$. As can be seen in Table 4, the system is very sensitive to the amount of non-ambulant people, affecting the time it takes to decontaminate the whole population.

Table 4: Analysis of Effect of Percentage of NonAmbulants.

\begin{tabular}{|l|c|c|c|}
\hline \multicolumn{1}{|c|}{ Run } & $\begin{array}{c}\text { \% non- } \\
\text { ambulants }\end{array}$ & $\begin{array}{c}\text { Time to com- } \\
\text { plete decon- } \\
\text { tamination } \\
\text { (hours) }\end{array}$ & $\begin{array}{c}\text { Number of } \\
\text { firefighters } \\
\text { required }\end{array}$ \\
\hline Baseline & 10 & 17.94 & 934 \\
\hline $\begin{array}{l}\text { No Non- } \\
\text { ambulants }\end{array}$ & 0 & 10.24 & 562 \\
\hline $\begin{array}{l}\text { Low Non- } \\
\text { ambulants }\end{array}$ & 4 & 12.79 & 686 \\
\hline $\begin{array}{l}\text { High non- } \\
\text { ambulants }\end{array}$ & 25 & 30.37 & 1560 \\
\hline
\end{tabular}

Figure $5 \mathrm{~A}$ illustrates the time taken to decontaminate the population under study, under different scenarios of non-ambulant casualties. Figure $5 \mathrm{~B}$ presents the number of firefighters required to man the stations in the different scenarios.
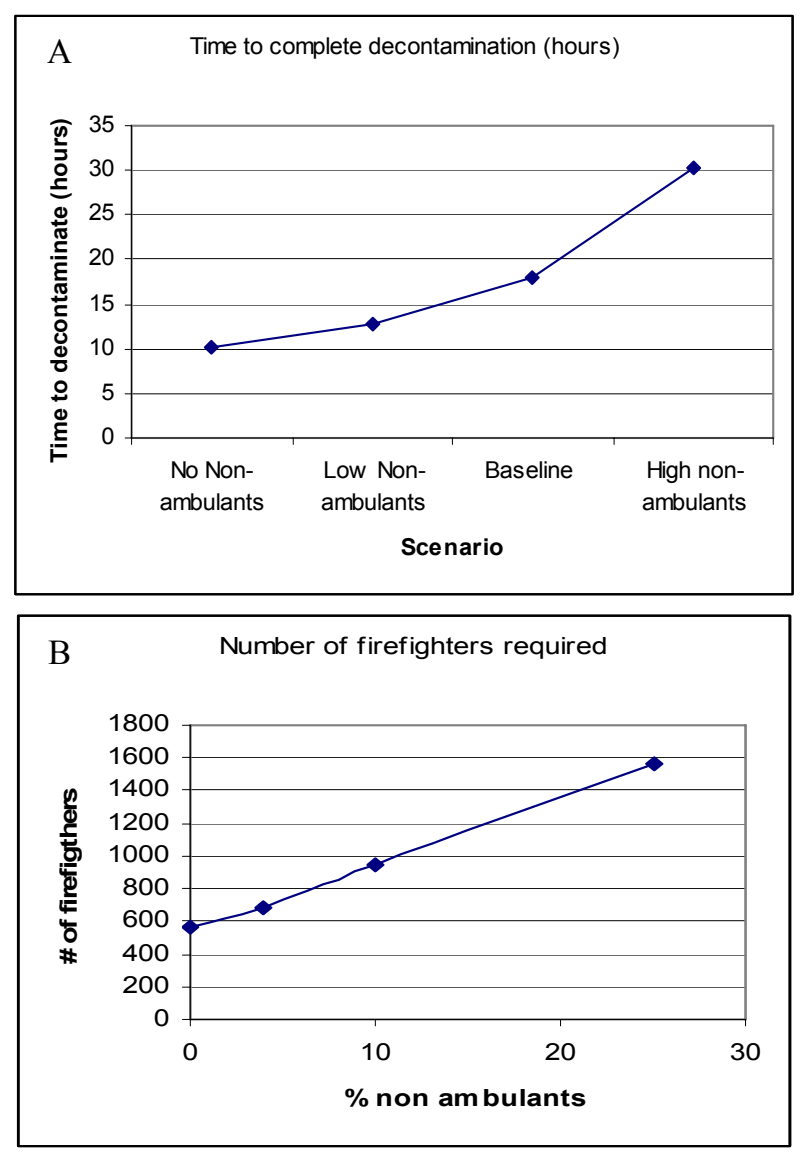

Figure 5: Time Taken to Decontaminate 20000 People with Different Rates of Non-Ambulant Casualties

There is an almost linear relation between the percentage of non-ambulant people and the time and manpower required to decontaminate the population. Since the assumption is that ambulant and non-ambulant casualties can freely go to any tent, a solution for this delay could be to dedicate a number of tents to deal with non-ambulants, while the rest can focus on dealing with the bulk of the ambulant population. For the example presented here, 16 tents can be dedicated to ambulant patients and deal with the population in 11 hours, while the other tents start processing non-ambulant casualties. When the 16 tents dealing with the ambulant population finish, they can then change to treat non-ambulants, giving a total decontamination time of 15.56 hours (on average) for the whole of the population.

Other results that are obtained from this model are the number of firefighters required for the operation of the decontamination units based on the type of PPE used. Runs 5, 7 and 9 in Table 5 consider the effect of firefighters operating for only 20 minutes in a Gas Tight Suit. Runs 5,8 and 10 consider the effect of raising this limit to 40 minutes.

Other scenarios analyzed were the possibility to "mass 


\section{Albores and Shaw}

Table 5: Experimentation with Different Personal Protection Equipment.

\begin{tabular}{|c|c|c|c|c|c|c|}
\hline Run & $\begin{array}{l}\text { Max time } \\
\text { for fire- } \\
\text { fighter in } \\
\text { suit } 1 \\
\text { (mins) }\end{array}$ & $\begin{array}{l}\text { Time } \\
\text { until } \\
\text { can } \\
\text { change } \\
\text { suit } \\
\text { from } \\
\text { type } 1 \\
\text { (mins) }\end{array}$ & $\begin{array}{l}\text { Max time } \\
\text { for fire- } \\
\text { fighter in } \\
\text { suit } 2 \\
\text { (mins) }\end{array}$ & $\begin{array}{l}\text { Time } \\
\text { until } \\
\text { can } \\
\text { change } \\
\text { suit } \\
\text { from } \\
\text { type } 2 \\
\text { (mins) }\end{array}$ & $\begin{array}{l}\text { Max } \\
\text { time } \\
\text { for } \\
\text { fire- } \\
\text { fighter } \\
\text { in suit } \\
3 \\
\text { (mins) }\end{array}$ & $\begin{array}{l}\text { Num- } \\
\text { ber of } \\
\text { fire- } \\
\text { fighters } \\
\text { re- } \\
\text { quired }\end{array}$ \\
\hline 5 & 20 & 240 & 60 & 600 & 120 & 934 \\
\hline 6 & 40 & 240 & 60 & 600 & 120 & 734 \\
\hline 7 & 20 & 120 & 60 & 600 & 120 & 742 \\
\hline 8 & 40 & 120 & 60 & 600 & 120 & 686 \\
\hline 9 & 20 & 60 & 60 & 600 & 120 & 686 \\
\hline 10 & 40 & 60 & 60 & 600 & 120 & 672 \\
\hline
\end{tabular}

disrobe" people and then having them wait for showers and re-robing, arrival patterns of tents and replenishment for disrobing and re-robing.

\subsection{Resources Allocation Model}

The resources allocation model analyses the time it takes for an "adequate" response to arrive at the scene of a disaster. As indicated before, this model provides initial response time, the arrival profile of crews/equipment to the scene and the actual duration of the event if not all resources are available (e.g. pumping $\mathrm{x}$ amount of water will take longer if you have 4 pumps than if you have 7 pumps). Figure 6 presents a snapshot of the scenario input page in the Excel interface. (Note: crews are only critical when analyzing mass decontamination events, hence for USAR and water related incidents, the resource was considered to comprise both equipment and crews)

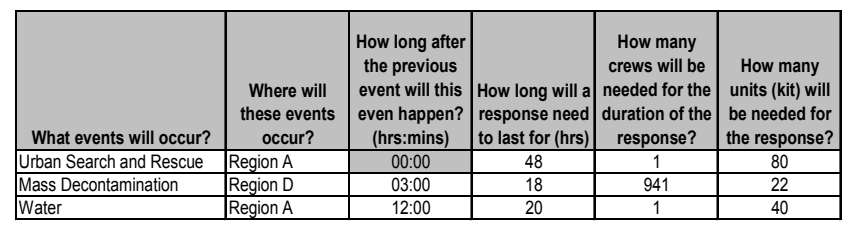

Figure 6: Scenario Input to the Resource Allocation Model

By running the model under this scenarios and assigning where each location can go to in order to request support (see Figure 7), the model analyses travel times and arrival times.

\begin{tabular}{|lll|}
\hline Region A & First take crews and kit from: & Region A \\
& Second take crews and kit from: & Region B \\
& Third take crews and kit from: & Region E \\
& Finally take crews and kit from: & Region F \\
\hline & & \\
\hline Region B & First take crews and kit from: & Region B \\
& Second take crews and kit from: & Region A \\
& Third take crews and kit from: & Region D \\
& Finally take crews and kit from: & Region E \\
\hline
\end{tabular}

Figure 7: The Order of "Borrowing" Resources from Other Locations
Figure 8 presents a typical graph obtained when running the model. In this case, it indicates that 40 units were required to tackle the flooding event presented in Figure 6 (this event started at $\mathrm{T}=15$ hours). The first 12 units arrive from the location the event is happening (Region $\mathrm{A}$ in this case) after 45 minutes. A further 10 units arrive from Region $\mathrm{F}$ and 14 units from Region $\mathrm{B}$ at $\mathrm{T}+3$ hours from the beginning of the event and the remaining 4 units needed arrive from Region $\mathrm{F}$ at time $\mathrm{T}+6.54$ hours. The analysis of arrival data to an incident, in conjunction with the modification of crews and equipment allocation will allow the study of different allocation configurations and the study of their effect on the operational effectiveness required to respond to different types of attack.

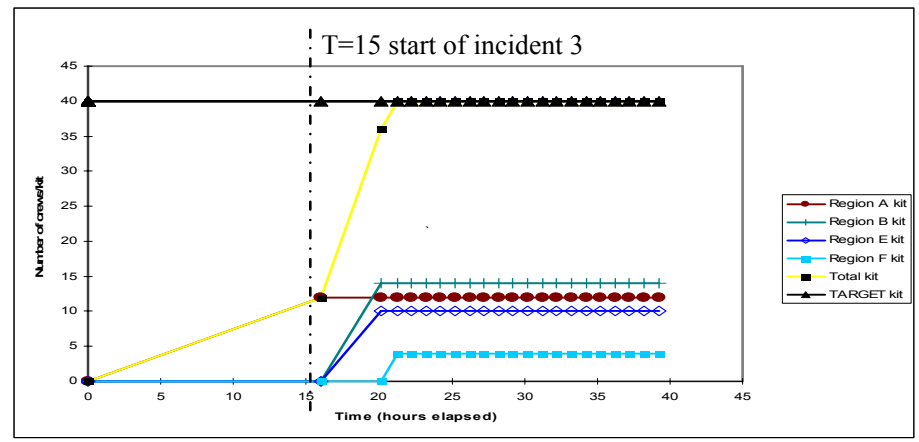

Figure 8: An Example "Weight Of Attack" Graph For Incident 3 .

Figure 9 shows the response profile for our Event 2, the mass decontamination of 20000 people. The initial data for Event 2 inputted in Figure 6 came from the result of the Mass decontamination model. In the resource allocation model we can test whether the level of response suggested by the mass decontamination model is achievable.

This event started at time $\mathrm{T}=3$ hours, and we can see that we are able to get 340 firefighters and 18 Mass decontamination tents (Figure 10) from Region D after 1 hour of the event starting. We can then go back to the mass decontamination model and test the response that we could obtain from this profile. This exercise illustrates the complementary nature of the two models and how they can inform each other in order to make a better decision when allocating resources to the individual regions.

\section{DISCUSSION}

The decision making related to the buying of equipment and planning for terrorist attacks is a complex one, mixing operational requirements with budgetary concerns and political considerations. The use of simulation allowed to take into account the operational aspects, relate to the budgetary concerns and presented a platform to communicate these aspects to inform decision making. The building 


\section{Albores and Shaw}

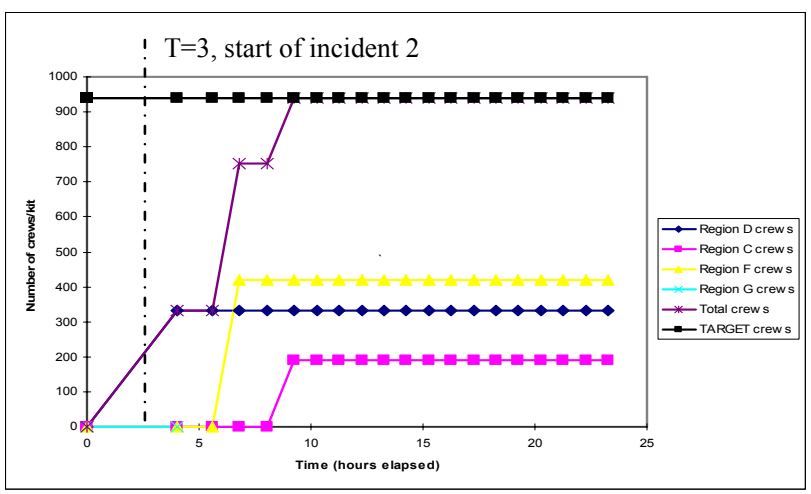

Figure 9: Crew Response to Incident 2: Mass Decontamination of 20000 People.

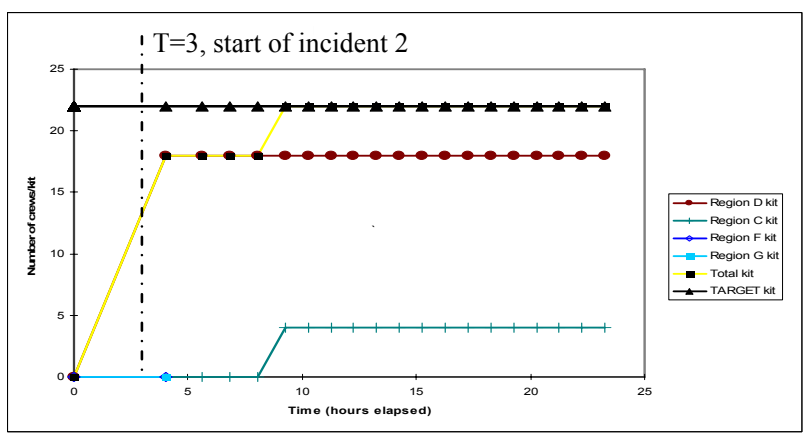

Figure 10: Equipment Response to Incident 2: Mass Decontamination of 20000 People.

model process was started at a stage in the decision making process in which some of the decisions had already been made (for example, how much equipment to buy) and other were still to be made (e.g. where to allocate resources, whether to have a central depot or distributed resources). The implementation of the model for the actual decision making is still underway at the time of writing.

The mass decontamination model was fairly straightforward to build and experiment with. The process is certainly well defined, data is available from exercises conducted by the fire service in conjunction with other emergency services and in general there was more consensus as to what the process looked like, what the intended outcome of the process was and what metrics should be used to gauge the success of this process (X amount of people decontaminated in Y hours). This certainty allowed the building of a model that could be easily populated with a particular scenario and analyzed.

The model has given some early indication as to what the factors more likely to affect the operation of the mass decontamination units are: percentage of non-walking casualties, time needed to spend in a particular PPE, disrobing strategy (i.e. mass disrobing vs. batch disrobing).

One particular aspect of this model is the analysis of the amount of firefighters required to man the decontamination units for the duration of the response. This aspect had to be considered because the amount of time spent in a PPE can be as low as 20 minutes, before they need replacement. The implication of having such a short time of operation in PPE is that in order to man one station for one hour you need to have 18 firefighters (6 people needed at any given time). When scaling this to the type of operation required to treat thousands of people, the implications for manpower requirements become considerable. Having this factor to be considered in the model is therefore essential. The analysis of different scenarios (e.g. operating in full gas-tight suits for the first hour, while conditions are evaluated and then changing to another PPE) proved to be beneficial for the planning of these events.

\subsection{Resource Allocation Model}

The modeling of resource allocation proved to be more complicated than the mass decontamination. The process is more complex and as a result not as well defined. It had the added difficulty of dealing with three different capabilities, each one with different process owners and with sometimes conflicting requirements.

The modeling can be used as a way of getting consensus between the parties regarding what a process looks like and what are the measures they require for these processes. At the end, a number of assumptions had to be made in order to arrive to a working model. As explained above, model was created to be as generic as possible, in order to deliver a model that could be tested and validated with the data that was available at the time, but that allowed new, more reliable data to be incorporated as it became available.

By using the Excel interface, the inputs to the model can be made without the user having to go into the simulation. This can allow non-simulation people (e.g. brigade chiefs) to experiment with the system and understand the implications of their decisions on the overall response to an incident.

The decision making related to the buying of equipment and planning for terrorist attacks is a complex one, mixing operational requirements with budgetary concerns and political considerations. Simulation allowed taking into account the operational aspects relate to the budgetary concerns and presented a platform to communicate these aspects to inform operational and tactical decisions.

\section{CONCLUSIONS}

This paper presents a case study which illustrates how to model the preparedness for making an emergency response to a terrorist attack. Two DES models were built, one dealing with mass decontamination in case of a chemical or biological attack and the other with resource allocation across different location and the effect of these allocations in the response to different types of incident. The models 


\section{Albores and Shaw}

were useful to gain understanding of processes which were ill-defined and of which little experience existed.

In the project which inspired this paper, the modeling exercise provided an effective discussion board in which to focus the attention of different process owners. This enabled the owners and modelers to build a joint view of what the objectives were, how to measure them and what owners had to contribute to achieve this. In this sense the models have already contributed to improving the preparedness for a terrorist attack, although their impact on the actual decision making is still ongoing at the time of writing.

\section{REFERENCES}

Aaby, Kay, Daniel T. Cook, Jeffrey W. Herrmann, Jordan, Carol and Wood Kathy. 2004. Simulating a mass vaccination Clinic. Public Health Reports article submission. Available online via http: / / www. isr. umd. edu/Labs / CIM/proj ects/clinic/hcms.pdf [Accessed February 15 2005]

Brady, Thomas F. 2003. Emergency management: Capability analysis of critical incident response . Proceedings of the 2003 Winter Simulation Conference, Ed.:.S. Chick, P. J Sánchez, D. Ferrin, and D. J. Morrice, 1863-67 New Orleans, Louisiana .

Cowdale, Alan . 2003. Traffic and road planning simulation: simulation modelling in support of emergency fire-fighting in Norfolk. Proceedings of the 2003 Winter Simulation Conference Ed..S. Chick, P. J Sánchez, D. Ferrin, and D. J. Morrice, 1707-10. New Orleans, Louisiana

Farahmand, Kambiz,. 1997 Application of simulation modeling to emergency population evacuation. WSC '97: Proceedings of the 2005 Winter Simulation Conference ed. S. Andradóttir, K. J. Healy, D. H. Withers, and B. L. Nelson, 1181-88 New York, NY, USA: ACM Press.

Greasley, A. (2004). Simulation modelling for business. Ashgate Press. UK.

Gul, Noreen. 2005. Modelling ambulance response times. Young Operational Research Conference YOR14 Ed. Andrew Tusson, J Keefe, Edgar Meyer, and Mark. Ramsay.

Hupert, Nathaniel, Alvin Mushlin, and Mark A. Callahan. 2002. Modeling the public health response to bioterrorism: Using discrete event simulation to design antibiotic distribution centers. Medical Decision Making 22: 1-9.

Jain, Sanjay, and Charles McLean. 2003. A framework for modeling and simulation for emergency response. Proceedings of the 2003 Winter Simulation Conference Editors:.S. Chick, P. J Sánchez, D. Ferrin, and D. J. Morrice, 1068-76.

\section{AUTHOR BIOGRAPHIES}

PAVEL ALBORES is a lecturer in the Operations and Information Management group at Aston Business School, Birmingham UK. His research interests are: Manufacturing Simulation, Business Processes Simulation, e-business, Supply Chains and networked organizations and Information Technology in the manufacturing context. Pavel has an special interest in composition in simulation. He can be reached at $<\mathrm{p}$.alboresaaston.ac.uk $>$ and his Web address can be found at <http: / / www abs.aston.ac.uk/newweb/staf f/detail.asp?sfldStaffID=A0000523>

DUNCAN SHAW is a Senior Lecturer in Aston Business School, Birmingham, U.K. He has a BA and a PhD from Strathclyde University, Glasgow. His research interests include structuring complex problems, supporting strategic decision making and implementing strategy, crisis response, simulation. In research and consulting capacities he has recently worked with the Health and Safety Executive (UK), Her Majesty's Nuclear Installations Inspectorate and the Scottish Executive, in addition to numerous private and public organizations. His email address is $<$ d.a.shawdaston. ac.uk $>$ and his web page can be found at:

http: / /www.abs.aston.ac.uk/newweb/staff / detail.asp?sfldStaffID=A0000274 